\title{
A Preliminary Study on Improving the Teaching Quality of Chinese Language and Culture for International Students
}

\author{
Lingli Zhang \\ Chongqing University of Technology, Chongqing, 400054, China.
}

\begin{abstract}
With the rapid development of my country's economy and the rapid advancement of its international status, the trend of learning Chinese language and culture has set off worldwide. Therefore, how to effectively improve the Chinese language level of foreign students coming to China has become a problem that many teachers need to solve. The author starts with the factors that affect the improvement of foreign students' Chinese proficiency, looking for teaching methods to ensure the rapid improvement of teaching quality, and hopes to provide references for other teachers.

Keywords: Teaching Quality; International Students in China; Higher Education; Chinese Language and Culture

The development of the economic era has made the exchanges of various countries increasingly close, and it has been constantly highlighted in the cultural field. With the improvement of my country's international status, more and more foreign students come here to study in China, hoping to learn Chinese culture with profound values. Because Chinese language and culture cover a wide range of content, it is very difficult for many international students to learn. This requires teachers to be able to innovate and improve the teaching activities according to the actual learning needs of foreign students when conducting teaching activities, so as to help them better complete the process of knowledge learning and ensure the effective rise of teaching quality.
\end{abstract}

\section{Factors influencing the improvement of foreign students' Chinese proficiency}

\subsection{Outdated teaching methods}

Although foreign students have a certain foundation in Chinese, for many students, Chinese culture has a long history, and the meaning and pronunciation of various words often make many foreign students feel at a loss when studying. When teachers teach Chinese language and culture, they do not analyze students' knowledge reserves, learning difficulties, and the basics of Chinese, which leads to the use of indoctrination and old methods to carry out teaching activities. This not only severely inhibits the motivation of students to participate in the learning of classroom knowledge, and a rigid and boring learning environment, but also fails to enable students to be driven by interest to ensure the effective improvement of learning quality. In addition, Western institutions rarely use the teaching mode in which teachers unilaterally explain knowledge. Therefore, under this old teaching method that inhibits the thinking ability of foreign students, not only the students' learning efficiency is seriously reduced, but also it is difficult to show the Chinese language and culture. In-depth discussion of cultural values, which seriously hampered the effective development of classroom teaching activities.

\subsection{The content of the textbook does not match}

When many colleges and universities choose Chinese language and culture textbooks, they generally use oral teaching and basic textbooks, which are very suitable for students studying on the basis of zero Chinese. However, the general students who come to China not only have active thinking consciousness, but also have a certain Chinese language foundation, so this basic general textbook cannot meet the learning needs of students, and the Chinese 
language and cultural level is difficult to improve, which leads to a serious decline in the quality of classroom teaching. . In addition, international students in China usually come from different countries. This kind of language textbook that ignores the cultural background of students also makes it difficult for students to mobilize their enthusiasm when participating in classroom knowledge learning, which leads to the difficulty of effectively improving students' learning efficiency.

\section{The main ways to improve Chinese language level of foreign students in Chinese language and culture classroom}

\subsection{Improve teaching methods}

Teachers want to ensure the effective improvement of the quality of Chinese language and culture classroom teaching. They need teachers to be able to innovate their own teaching perspectives according to the development of the times. By breaking the backward teaching concept, they can find the motivation that can fully inspire foreign students to participate in classroom knowledge learning. . This will not only enable students to exert subjective initiative to improve learning efficiency, but also promote the high-quality development of teaching activities. Due to the differences in Chinese language level, thinking consciousness, cultural background and learning ability of foreign students, teachers can use cooperative learning methods to divide class students into several learning groups according to their learning needs when conducting teaching activities. This will not only enable students to learn Chinese language and culture knowledge in the sense of learning pleasure, but also ensure the smooth improvement of classroom teaching quality in the process of mobilizing foreign students' inquiry ability and thinking consciousness.

\subsection{Enrich teaching materials}

Due to the large differences in international students' Chinese language foundation, cultural background, and knowledge acceptance ability, colleges and universities need to enrich the content of teaching materials according to the actual situation of students. For example, through the integration of emerging Chinese language and cultural education resources, schools can encourage teachers to write their own textbooks according to the actual situation of students, so that students can ensure the improvement of learning efficiency in the process of meeting learning needs. At the same time, teachers can also use the Internet platform to integrate educational resources and innovate the content of teaching materials in the form of video, animation, audio, etc. This can not only effectively arouse the enthusiasm of foreign students, but also promote the high-quality development of teaching activities.

\subsection{Introduce teaching evaluation mechanism}

Teaching evaluation, as a key content to measure whether the classroom teaching activities are carried out in an orderly manner, can enable teachers to improve teaching plans in a targeted manner according to the actual learning feedback of students, and then achieve the purpose of establishing high-quality teaching classrooms. Therefore, colleges and universities need to actively introduce the teaching evaluation mechanism, change the previous mode of teacher evaluation of students, and ensure the comprehensiveness of the main body of teaching evaluation through the implementation of modes such as teacher-student mutual evaluation, teaching supervision, and student mutual evaluation. This not only makes it easier for students to find their own confusion in learning activities, but teachers can also combine students' learning needs with reasonable design of Chinese language and culture teaching content, and constantly improve students' language level, speculative ability, learning ability and communicative ability. To improve, and in the process of standardizing the behavior consciousness and thinking level of foreign students, to ensure the highquality construction of classroom teaching activities.

\section{Conclusion}

The Chinese language culture not only covers a wide range of content, but also for international students in Western countries, they often feel particularly strenuous when participating in learning activities, resulting in the difficulty of effectively improving classroom teaching efficiency. This requires teachers to conduct targeted improvement of teaching activities through analysis of students' knowledge acceptance ability and individual differences during the 
teaching work, which can not only mobilize the enthusiasm of foreign students to learn Chinese language and cultural knowledge, but also improve their At the same time as learning quality, it ensures the high-efficiency development of classroom teaching activities.

\section{References}

1. Liu Jihong. Exploring the second language culture teaching model based on the survey of learner needs_-Taking foreign students in the Chinese teacher training project in Malaysia as the object[J]. Overseas Chinese Education, 2019(04):115-125.

2. Tian Yan. On the cultivation of the organization and training ability of the Master of Chinese Language and Culture in International Education__ Taking the "Beijing Chinese Star Contest for Foreign Students" as an example[J]. Chinese International Communication Research, 2017(01):134 -142+159-160.

3. Li Jing. About the strategic position and countermeasures of the spread of Chinese language and culture in the internationalization of education by western medical students in China [C]. Liaoning Higher Education Society. Liaoning Higher Education Society 2013 Academic Annual Conference and the Fourth Session Abstract Collection of Papers for Young and Middle-aged Scholars Forum. Liaoning Higher Education Society, 2013:163. 